\title{
RESIGNIFICANDO A LACAN: USO DEL PSICOANÁLISIS EN LA CRÍTICA LITERARIA Y CINEMATOGRÁFICA DE ŽIŽEK
}

Yiyang $\mathrm{Wu}$

(Universidad de Sevilla)

yiyangwu2666@gmail.com

RESUMEN: El presente artículo se propone analizar los usos del psicoanálisis en la crítica literaria y cinematográfica de Žižek a partir de su resignificación sobre lo real, lo imaginario y lo simbólico de la teoría lacaniana. Se centra en las ideas como el gran Otro, la fantasía, el objeto a y la pulsión de muerte como herramienta hermenéutica para reinterpretar la literatura clásica y el cine moderno. Al final del texto se trata de aplicar la idea žižekiana en el análisis de algunos textos con fuertes matices psicoanalíticos y cuestionamientos sociales en la narrativa hispanoamericana contemporánea.

PALABRAS CLAVE: Žižek, Lacan, psicoanálisis, narrativa hispanoamericana.

\section{RESIGNIFYING LACAN: THE USE OF PSYCHOANALYSIS IN ŽIŽEK'S LITERARY AND FILM CRITICISM}

ABSTRACT: This article aims to analyze the psychoanalytic elements in Žižek's literary and cinematographic criticism, according to his redefinition of the real, the imaginary and the symbolic in Lacan's theory. Ideas such as the big Other, fantasy, object a and the death drive are used by him as hermeneutic tools to reinterpret classical literature and modern cinema. At the end of the article we will apply the ideas above to the analysis of some contemporary Spanish-American narrative, characterized by their strong psychoanalytic and psychosocial contents.

KEYWORDS: Žižek, Lacan, Psychoanalysis, Spanish American Narrative.

Terry Eagleton describe a Žižek como «el exponente más formidable del psicoanálisis o en la teoría cultural en general que ha surgido en Europa durante muchas décadas» ${ }^{1}$ (Eagleton, 1997: 8). Destacado por su capacidad de combinar la dialéctica de la negatividad hegeliana, el psicoanálisis lacaniano y la teoría ideológica althusseriana y marxista, Žižek aparece como uno de los filósofos más radicales y fructíferos en el panorama mundial, gracias a la perspectiva transgresora y la aplicación efectiva del psicoanálisis lacaniano en el terreno literario, cinematográfico y sociopolítico del siglo XX y XXI. Hay que tener en cuenta que, como muchos críticos contemporáneos (Agamben, Rancière, Butler), la crítica literaria y cinematográfica de Žižek se apoya en una sólida base filosófica, excediendo el terreno de lo artístico para llegar a lo ontológico. Partiendo de su reinterpretación de lo real, lo simbólico y lo imaginario de Lacan, en este artículo analizamos cómo el filósofo esloveno se apropia de la tradición psicoanalítica para aplicarla en la interpretación de la literatura universal y el cine

${ }^{1}$ «the most fomidably brilliant exponent of psychoanalysis, indeed of cultural theory in general, to have emerged from Europe in some decades» (Eagleton, 1997:8). 
contemporáneo que consumimos día a día en una época de posverdad. ${ }^{2} \mathrm{Al}$ final del artículo se procura utilizar los conceptos žižekianos en el análisis de la narrativa moderna y contemporánea de América Latina, sobre todo Argentina, uno de los países más influidos por la corriente psicoanalítica en las letras hispánicas.

\section{EL GRAN OTRO, LA FANTASÍA IDEOLÓGICA Y LA INTERSUBJETIVIDADDEL DESEO}

El reconocimiento del sujeto sobre el mundo a través del «estadio de espejo» ha sido el fundamento del psicoanálisis lacaniano. Según él, el niño tiene que desprenderse de la fase preedípica y de la experiencia pregenital para integrarse en el mundo simbólico dominado por el sistema paternalista que reprime al individuo con sus códigos. El niño se convierte en el sujeto castrado (\$) por la red intersubjetiva, que nos interpela intermitentemente con sus códigos, conductas, leyes, estéticas, lenguas y normas neutralizadas. Partiendo de la hipótesis lingüística saussuriana, Lacan recurre a la teoría semiótica para entender la realidad, que logra ser representada mediante un sistema de nombramiento y significación. Es un mundo intersubjetivo que funciona en nombre del padre: «la castración quiere decir que es preciso que el goce sea rechazado, para que pueda ser alcanzado en la escala invertida de la Ley del deseo» (Lacan, 2009: 789).

Sin embargo, difiriendo de la hipótesis saussuriana por la cual un significante concreto remite a un significado abstracto, en el mundo lacaniano se anula la existencia del significado. Lo simbólico está compuesto de puros significantes, cuya singularidad se distingue gracias a su distinción con los otros significantes flotantes. Por ejemplo, la palabra «día» no se refiere a algo concreto hasta que se compara con «noche», mientras que siempre hay momentos innombrables en el limbo. Para Žižek, la cadena de significantes que se remiten entre sí crea un hueco ontológico en el universo semiótico, que se vuelve cada vez más autorreferencial.

El psicoanálisis moderno niega así la idea platónica de que todas las apariencias son proyecciones de alguna noción sublime y elevada. Afirma la dimensión intersubjetiva de nuestro mundo, cuyo funcionamiento depende constantemente de la regla predominante de socialización. Los individuos se ven obligados a someterse a cierto tipo de autoridad y obedecer a los saberes neutralizados, interpelados a dar

\footnotetext{
${ }^{2}$ La idea de lo simbólico, lo imaginario y lo realsurgen a partir del análisis de la fase especular. Antes de lograr la percepción íntegra del yo, el niño no puede distinguir el punto de escisión entre su cuerpo y el mundo hasta que empieza a identificarse con su reflejo en el espejo. Debido a la imprecisión del espejo y el límite cognitivo, la figuración de la conciencia propia no es completa desde inicio y el niño termina conociéndose física y mentalmente gracias a lo imaginario. Lo simbólico ocurre en la etapa edípica donde el sujeto se somete al dominio de los discursos y las hablas socia les, enterrando su trauma inicial y la percepción primitiva del mundo, que es lo real lacaniano. Para él, lo real «no es más que el espacio de los fracasos de la simbolización [...] incapaz de transformarse para nosotros» (Lacan, 1972: 58). Es un mundo caótico, imposible de precisar con palabras concretas y prohibido para el mundo gestáltico. Aquellos tres mundos no son totalmente aislados, sino entrela zados y funcionan conjuntamente para influir en el comportamiento del sujeto.
} 
importancia a determinadas cosas. ${ }^{3}$ El mundo simbólico logra motivar y controlar la conciencia con la ayuda del «designante rígido» y «el punto de acolchonamiento», que ordenan los significantes dispersos y los hacen confluir en la misma palabra.

En la Segunda Guerra Mundial, el régimen nazi logra otorgar varias implicaciones a la palabra «judío»: son promiscuos, ávidos y amorales, y a la vez inteligentes. Estos denominados «puntos» ayudan a la formación del relato institucional, haciendo creer al mundo sobre su propia legitimidad, inocencia y naturalidad. De acuerdo con la lógica del acolchonamiento, un término (feminismo, izquierda, ecologismo, democracia y liberalismo) puede adquirir matices muy diferentes al vincularse con distintos significantes, proyectando la voluntad de una cierta colectividad que lo maneja. Un ecologista puede tener rasgos nacionalistas, abogando por la intervención obligatoria del Estado, o de perfil socialista, y culpa de todo a la explotación capitalista, o conservador, al pedir el retomo definitivo a la época bucólica. Un concepto como comunismo se puede degradar/gentrificar según el punto de enunciación en que se encuentra el interlocutor. El sistema que manipula los deseos colectivos se llama el gran Otro, que es rígido, hegemónico y obsceno. Una de sus metas es aparentar ser una totalidad holística y ordenada, capaz de explicarse a sí mismo borrando las disidencias y heterogeneidades.

La misma lógica funciona en la edición cinematográfica, cuando el director edita todos los planos con el motivo de darles un significado unificado y coherente ante los espectadores, invitándolos a entrar en aquel mundo simbólico y artificial. ${ }^{4}$ En Mirando al sesgo (2000), Žižek nos explica que la legitimidad de una idea suele ser autojustificativa, a través de la interpretación de la película Casablanca (1942), dirigida por Michael Curtiz. La trama es el típico triángulo amoroso: Rick, el protagonista de la historia, decide entre obligar a quedarse a Ilsa, su antigua amante, o dejarla escapar con su marido legítimo. El desenlace oficial de Casablanca es el abandono de Ilsa a Rick y su compromiso con el marido legítimo, un final «clásico» que conmueve a todo el mundo. Sin embargo, Žižek revela que al final del rodaje el guionista todavía vacila entre tres opciones distintas. ${ }^{5}$ Sostiene que todos los espectadores se sentirán igualmente conmocionados sea cual sea el desenlace que hayan elegido, porque el hecho de ser una película le ha dado suficiente legitimidad y cualquier fin puede adquirir una apariencia razonable gracias a las técnicas de montaje. La creencia en que cualquier fenómeno que

${ }^{3}$ La noción de la interpelación viene de Ideología y los aparatos ideológicos del estado de Louis Althusser. Se refiere a un grupo de señales, informaciones, conocimientos emitidos por la autoridad institucional para que el individuo pase pasivamente por el proceso de subjetivación, interpelado por las reglas del sistema (Althusser, 1988: 102). No obstante, en el mundo althusseria no o foucaultiano, la relación de poder se reproduce de acuerdo con la lógica bina ria del represor-reprimido, mientra s que en el mundo žižekiano podemos seralmismo tiempo los que imponen la regla y los que sufren por ella.

${ }^{4} \mathrm{La}$ relación audiencia-película se puede equiparar con la relación niño-mundo. Cuando se sientan en la sala, los espectadores empiezan a imaginar lo que va a suceder y se dan cuenta de la pasividad de su posición, porque la rea lidad que se les presenta en el primer plano está manejada por el Otro que no conocen. Cuando sale el segundo plano como significante pa ra definir y completar el primer plano, los espectadores entran desde lo ima gina rio en lo simbólico (Žižek, 2001b: 32). Así funciona el acolchonamiento cinematográfico, creando una falsa apariencia homogénea y orgánica, borrando las huellas de exterioridad. González Requena también utiliza el psicoanálisis en la crítica cinematográfica. Para él, el primer plano, prota gonizado muchas veces por roles femeninos, representa la Imago Primordial (la madre) con la que el sujeto empieza a entablar relaciones con el mundo (González Requena, 2018: 39).

${ }^{5}$ Opción A: Ilsa se va con el marido; B: Ilsa se queda con Rick; C: Uno de los hombres tiene que morir para que Ilsa no tenga que tomar la dolorosa decisión. 
se presenta resulta siempre explicable «oculta el hecho de que el propio final, retroactivamente, confiere la consistencia de un todo orgánico a los hechos anteriores» (Žižek, 2000: 122). El significado no proviene de una cadena de significantes lineal y coherente, sino que se produce casi retroactivamente: «el análisis produce la verdad; es decir, el marco significante que confiere al síntoma su lugar y significado simbólicos» (Žižek, 2003a: 88).

Fuera del terreno cinematográfico, el ejemplo constantemente utilizado por Žižek es la legitimidad de la monarquía. Una mentira largamente tolerada es que el poder de la monarquía reside en sí misma en vez de emanar del consenso ciudadano y la convicción de su valor incuestionable. La Revolución Francesa destruye la estructura cognitiva anterior y deja ver el sinsentido de esta. ${ }^{6}$ Por lo tanto, aquel tipo de autoridad virtual e inalcanzable (la monarquía, la democracia, el Dios, el Führer, el capital, la democracia) que tiene la apariencia natural e indudable se denomina como el «objeto sublime de la ideología». Žižek desmiente la idea kantiana sobre la cosa-en-sí que excede la esfera de conocimiento humano y que queda más allá de nuestro alcance.

Aquel espejismo conceptual suele ocupar el espacio central de nuestra vida y su legitimidad ridícula viene paradójicamente de la existencia del sistema simbólico, mundo en que todos los sujetos desempeñan una función en la cadena de significantes. Según la lógica intersubjetiva, los deseos no son más que el reflejo del «yo» incompleto proyectado en la alteridad, mientras que el gran Otro los aprovecha y crea compromisos y simulacros fantásticos (dinero, relación, estatus social, belleza) que perseguimos vanamente. El sujeto, engañado por el «propio» deseo, se esfuerza por situarse en el orden simbólico. Los mecanismos que realiza el gran Otro para reforzar la acción de desear se corresponden con la lógica de funcionamiento de la fantasía ideológica: «eso que los científicos llaman ley no es otra cosa que la condición de una repetición» (González Requena, 2010: 20).

En el centro del deseo, de todos los discursos que nos hacen desear algo, reina el vacío. 7 Žižek lo describe como una «imposibilidad central»y «un callejón sin salida que no es más que una estructuración de esa imposibilidad» (Žižek, 2000: 82). El objeto que ocupa el lugar de lo imposible reúne todas las cualidades simbólicas deseables. Es imposible acercarse a él porque tiene un núcleo vacío. Las damas frías en la antigua novela de caballería, los paisajes orientales en la literatura romántica, Venus en la leyenda griega o el icono de Coca-Cola en la sociedad de consumo, son objetos que llenan el hueco del gran Otro sublime. Funciona como «el espejo en el cual el sujeto proyecta su ideal narcisista...como un límite cuyo Más Allá es inaccesible» (Žižek, 2000: 138-139). Son objetos que en ningún momento tienen caracteres humanos, cuya legitimidad se debe solamente a la existencia de la estructura misma.

${ }^{6}$ Para filósofos como Žižek o Badiou, la Revolución Francesa puede considerarse como un acontecimiento que abre una fractura en la historia y explica retrospectivamente el pasado. Es una «dialéctica de exceso-defecto que deja ver que en el saber mismo se encuentran zonas de sombras de lo no simbolizado» (Carrasco-Conde, 2003: 506). El acontecimiento es un suceso que aparece como un surgimiento ex nihilo, que no puede razonar con la lógica causa-efecto y explica retroactivamente el fallo en el campo político anterior.

${ }^{7}$ Define el autor: «nuestra realidad común cotidiana, la rea lidad del universo social en el cual asumimos nuestros roles de personas decentes y bondadosas, se convierte en una ilusión basada en una cierta represión [...] esa realidad social no es entonces má s que una débil tela raña simbólica que la intrusión de lo real puede desgarrar en cualquier momento» (Žižek, 2000: 30). 
El autor toma el libro de ciencia ficción El árbol de manos (1988) de Ruth Rendell como ejemplo. Una madre está devastada por la muerte de su hijo y la abuela enloquecida le ha robado un niño para compensar la pérdida. Después de una serie de intrigas, ella acepta morbosamente a este hijo no biológico, porque «el niño me ha sido impuesto» (Žižek, 2000: 61). Según el esloveno, la aceptación final no se debe al cariño que ella tiene hacia el niño, sino a la idea del «hijo» que ya existe en la estructura cognitiva de la madre y ocupa aquel sitio sublime. A pesar de que el niño puede ser sustituido por cualquier otro, su hijo debe parecer «encontrado».

De acuerdo con Žižek, la diferencia entre la literatura realista y la modema reside en el hecho de que la anterior intenta reproducir todo el sistema semiótico para encubrir su esencia vacía, y la posterior, enseñar directamente la falta de la cosa-en-sí en el mundo simbólico. La narrativa tradicional apela a las descripciones minuciosas y globales de los detalles cotidianos, con el motivo inconsciente de completar el agujero negro en el mecanismo representativo. El ejemplo que ha tomado es el primer encuentro de Madame Bovary con su amante en la calesa. Flaubert se limita a escribir todo lo que no sea el sexo para implicar su existencia: la calle, la cortina en que se cobijan, el deambular del caballo... Este fragmento es tachado de lujurioso por el fiscal, pese a la ausencia del elemento erótico, porque todo el mundo ha presupuesto que hay una verdad lujuriosa dentro de la calesa. Tanto el fiscal como la masa están obsesionados por la existencia de «algo» detrás del simulacro. Teniendo en cuenta el contexto puritano en aquel entonces, aquel elemento imaginado es sin duda el sexo mismo.

En cambio, la literatura en la vanguardia se dedica a visibilizar la ausencia esencial en el ser. En este sentido, Esperando a Godot inaugura el vanguardismo: «toda la acción fútil y absurda de la obra se despliega en el marco de espera» y se espera que finalmente ocurra algo, sabiendo muy bien que «Godot nunca llegará, es sólo un nombre de la nada, de una ausencia central» (Žižek, 2000: 240-241). Las alegorías y símbolos exuberantes que remiten rizomáticamente a otros significantes en los textos de vanguardia muestran la paradójica presencia de aquel punto ausente. El Aleph de Borges es aquel lugar absolutamente inaccesible e imposible de precisar con palabras concretas, convertido sorprendentemente en el centro de todos los deseos humanos, apropiado por los hombres. ${ }^{8}$ En el mismo cuento, el autor argentino critica la obsoleta y exhaustiva forma de narrar de acuerdo con la cadena de significación, en vez de atravesarla: «se proponía versificar toda la redondez del planeta [...] tiene la perfección formal y el rigor científico, porque ese dilatado jardín de tropos, de galanuras, no tolera un solo detalle que no confirme la severa verdad» (Borges, 2011: 166 y 169, la cursiva es mía).

En vez de creer en la ilusión de que la observación minuciosa de las apariencias nos puede acercar a la verdad, los creadores de la vanguardia no se contentan con reproducir con «rigor científico» el mundo superficial que vivimos. Las imágenes finales de Belle de Jour (1967) de Luis Buñuel y Blow-up (1966) de Michelangelo Antonioni reflejan directamente la falta de aquel punto central que deseamos perpetuamente: en la película del cineasta español, la calesa que encarna el deseo erótico de Séverine es vacía y se encamina a un punto incierto, mientras que en Blowup, el fotógrafo-detective intenta captar las huellas del asesinato y solo descubre que dos hippies están jugando un partido imaginario de tenis en el lugar del crimen.

\footnotetext{
${ }^{8}$ Dice el narrador de Borges: «vi en Aleph la tierra, vi mi cara y mis vísceras, vi tu cara, y sentí vértigo y lloré, porque mis ojos habían visto ese objeto secreto y conjetural, cuyo nombre usurpan los hombres, pero que ningún hombre ha mirado: el inconcebible universo») (Borges, 2011: 174).
} 
Siguiendo la argumentación anterior, sostiene que la renovación radical que hace el texto postmoderno sobre aquel núcleo vacío consiste en materializarlo directamente como un objeto cotidiano, cuyo efecto aterrador empieza a funcionar de manera absurda. Para el filósofo, El castillo y El proceso de Kafka son posmodernas por la desacralización del objeto sublime, reduciendo lo autoritario a algo cotidiano, podrido y excedente de deseo..$^{9}$ El tribunal supremo en El proceso aparece en una lavandería y es presidido por una mujer obscena. La operación desmitificadora nos hace parecer que «una letra muerta está en realidad viva, respira, late» (Žižek, 2000: 248). Aquí la afirmación žižekiana coincide con el giro antiesencialista y subjetivista en el pensamiento contemporáneo: la Razón no está dada sino construida y el modo de su construcción depende cada vez del análisis discursivo y lingüístico. Se pregunta con más frecuencia cómo se fabrica/transmite un hecho como algo verdadero en vez de creer en su naturalidad incuestionable.

Sostiene luego que la convicción acuñada en la subconsciencia de cada uno sobre la existencia de algo natural y objetivo es el pilar que sustenta nuestra vida, cuya supresión conduce a la pérdida de la sensación de realidad. Aferrarse al simulacro fantástico es el cinismo contemporáneo: sabemos que algo está mal en el sistema capitalista, pero lo pasamos por alto y fingimos no saberlo para estabilizarnos en la colectividad y garantizar aquel «funcionamiento libidinal de la burocracia efectiva y real» (Žižek, 2003a: 65). La sabiduría del niño en el cuento «El traje nuevo del emperador» no consiste en reconocer que el rey está desnudo sino revelar, sin escrúpulos, el hecho de que todos los demás fingen que no lo reconocen. El consenso comunitario da por sentado un hecho tan ridículo como la desnudez del rey. No obstante, los individuos socializados lo necesitan para dar sentido a la vida y pertenecer a los espacios correspondientes en la realidad: «sólo a través del fantasma se constituye el sujeto como desecante» que logra «especificar su objeto y situar la posición que el sujeto asume» (Žižek, 2003a: 22). La paradójica y duradera existencia de la fantasía colectiva muestra lo efectivo del mecanismo de manipulación capitalista.

\section{EL OBJETO A Y EL GOCE TRAUMÁTICO}

¿Qué es lo que verdaderamente desean después de reconocer lo engañoso de lo simbólico? Aunque una parte de nuestro deseo está condicionada por la regla capitalista, siempre hay algo inquietante que se asocia con los impulsos más profundos del «ello» freudiano o lo real lacaniano. A diferencia de Althusser, que cree en la fuerza omnipresente de la ideología en el mundo simbólico, Žižek cree que existe una línea de fuga que se desliza de la codificación represiva. Muestra la fuerza desterritorializadora de lo inconsciente y extático al escaparse del reino de discursos y palabras. Se llama el objeto a (objet petit a), que pertenece precisamente al intersticio entre lo real y lo simbólico, marcando un vacío cognitivo, un espacio en blanco, un remanente inalienable en el proceso de subjetivación y una mancha perpetua en el sistema lingüístico. La interpelación nunca es plena, cuyo fallo se traduce en la resistencia del

${ }^{9}$ El adjetivo obsceno tiene más implicación ontológica que erótica. El sujeto no para de adivinar qué quiere el gran Otro místico, que a ctúa como una «mujer puta» en la vulgar sabiduría chovinista y nunca nos dice la verdad: «cuando ella dice ¡No! a nuestras propuestas, en rea lidad quiere decir un doble ¡Sí!» y «su verda dero deseo es lo opuesto a su demanda»(Žižek, 2003a: 155). 


\section{Yiyang Wu}

sujeto con la pregunta «¿Che Vuoi?»: «Me estás diciendo esto, pero ¿qué es lo que quiere con ello?, ¿qué es lo que pretendes?» (Žižek, 2003b: 154). ${ }^{10}$

Jesús González Requena también sostiene que aquel criterio se puede aplicar a la propia teoría lacaniana, porque lo que Lacan quiere decir siempre es otra cosa y «lo que ha dicho al parecer no sería lo que había querido decin» (González Requena, 2012a: 11). Cuestionar ante la demanda del Otro ayuda al sujeto a desear de manera analítica. En la película La última tentación de Cristo, Cristo se reencarna en un ser ordinario que no puede conciliarse con su misión de redimir la humanidad, incluso en el momento de la crucifixión. Según Žižek, el fracaso de la codificación constituye la razón de existencia del sujeto bajo la dictadura de lo simbólico:

El significante desmembra el cuerpo, que evacua el goce del cuerpo, pero esta «evacuación» (Jacques-Alain Miller) nunca se lleva a cabo del todo; esparcidos por el desierto del Otro simbólico, siempre hay algunos restos, oasis de goce, las llamadas «zonas erógenas». Son precisamente estos remanentes a los que está ligada la pulsión freudiana: circula, pulsa en torno a ellos. Estas zonas erógenas están designadas con la D (demanda simbólica) porque no hay nada natural, biológico, en ellas: qué parte del cuerpo sobrevivirá a la «evacuación del goce» lo determina, no la fisiología, sino cómo haya sido diseccionado el cuerpo por el significante (Žižek, 2003a: 169).

La idea de goce/placer ha sido largamente subestimada por la filosofía platónica y cartesiana. Al ubicar la racionalidad dogmática y el razonamiento abstracto por encima de la sensibilidad humana, el compromiso con las polis por encima de las dudas y placeres individuales, empieza el proceso de codificación, dirigido a convertir a los sujetos en meros seguidores de los dogmas. El sistema quiere privarlos de los verdaderos goces a través de la domesticación de lo real dentro de ellos. Al desobedecer el proceso de codificación, se produce un goce desconcertante.

Desde la perspectiva psicoanalítica, el goce (Jouissance) representa una transgresión ontológica, superando la dimensión del placer carnal, que es un goce «pretendidamente adecuado a la relación sexual» (Lacan, 1995: 78). Surge a lo largo de la búsqueda de lo incodificable (objeto a) para el superyó simbólico. Es una existencia schrödingeriana en la telaraña de significantes, e imposible de precisar para el metalenguaje universal. El encuentro con el objeto a produce la conmoción, la tristeza y el vértigo y la revelación. Tiene una relevancia vital, porque imposibilita el discurso simbólico y motiva a los sujetos a fugarse de la ilusión capitalista: «el objeto a no es lo que nosotros deseamos, aquello que tratamos de obtener, sino, más bien, aquello que pone en movimiento nuestro deseo» (Žižek, 2011: 51). El sujeto, desarraigado desde el nacimiento al apartarse del espacio intrauterino, lleva toda su vida hallando en el mundo simbólico aquella experiencia perdida: busca el objeto a que se escapa del reino represivo de símbolos para retornar a la experiencia prenatal.

El goce žižekiano no es una respuesta pervertida y erótica bajo la sombra del poder estructural (Foucault, Marcuse, Bataille), sino que constituye algo incodificable en el mundo de lo real en el proceso de subjetivación. Aparece como el fracaso de la interpelación ideológica, el fallo del intento de tapar la ausencia central en la cadena de significación. Para el esloveno, el sujeto es lo que es gracias a aquella parte

${ }^{10}$ Según Sigmund Freud en La interpretación de los sueños, encontramos en los actos fallidos, los errores verbales y los defectos de escritura, elementos que se escapan del autocontrol de sujeto. 
insubjetivable: «el sujeto es por lo tanto estrictamente opuesto a la subjetivación» (Žižek, 2003b: 227). ${ }^{11}$ Es imposible otorgar a objeto a una descripción continua y coherente: el objeto a tiene que desplazarse entre uno y otros objetos de deseo, cambiar constantemente su contenido y aparecer de manera efímera porque, una vez expuesto al mundo simbólico, corre el peligro de ser definido. Según el propio Lacan: «cabe decirlo: esta exigencia de lo Uno, como ya podía hacérnoslo prever extrañamente el Parménides, sale del Otro. Allí donde está el ser, es exigencia de infinitud» (Lacan, 1995: 18). Por lo tanto, a pesar de que ya adquirimos el objeto que hemos querido, el deseo nunca se satisface plenamente: la plenitud siempre está por llegar. Es un fenómeno presemiótico que sucede inesperada e imprevistamente: «es el lugar del sujeto; hasta entran ganas de decir que es su imposible Ser-ahí, DaSein. El goce es el infame heimliche que al mismo tiempo es lo más unheimliche, siempre está ya ahí y, justamente por eso, perdido ya para siempre» (Žižek, 2011: 58).

El encuentro con lo real produce a la vez un placer desconcertante y una herida chocante: el eufemismo siempre viene paralelo al horror durante la transgresión. Por una parte, el objeto a ofrece la razón de existencia para el sujeto, cuando provoca todos los deseos subversivos. Por otra parte, al acercarse demasiado al meollo de lo realtraumático, siente una angustia y extrañeza indecible. El origen del mundo (1866), el cuadro escandaloso de Gustave Courbet, muestra la invasión de lo real en los momentos inesperados. Es un cuadro realista que reproduce, punto por punto y con excesivo rigor, los detalles de unos genitales femeninos. Lo extraño reside en la minucia con que intenta reproducir el mundo de las cosas y su fallo automático. En vez de convertirse en una pieza artística fiel a la realidad, la reproducción excesivamente rigurosa de la intimidad femenina provoca nuestra extrañeza y goce durante la contemplación. Por su «desublimación radical», la obra se convierte en el punto intermediario del arte realista y vanguardismo (Žižek, 2001a: 37). ${ }^{12}$ El goce en el vanguardismo consiste en mostrar el momento en que la realidad se vuelve real. Para Žižek, los cuadros (Este no es una pipa y La tumba de luchadores) de René Magritte muestran la grieta entre la realidad y lo real: sus títulos mantienen una relación ambigua con el contenido, poniendo en entredicho la legitimidad del sistema de designación.

La cualidad impronunciable y desconcertante del goce motiva su exhaustiva reproducción en las obras literarias y cinematográficas. Al final de la película predilecta de Žižek, La boda de mi mejor amigo (1997) de Paul John Hogan, se presenta un baile apasionante en medio de la boda entre dos invitados. Son los dos exnovios del matrimonio que intentan fastidiarlo y provocarle celos. No obstante, aquella pareja «falsa» parece más feliz, convincente y alegre que la pareja verdadera, legitimada por las ceremonias y los procesos civiles. El baile gozoso desmiente la noción del matrimonio legítimo, forjada por el mundo gestáltico. La creación artística en la modernidad gira en torno a aquel punctum ontológico que paradójicamente hay que revelar. En el cuento «The real thing» de Henry James, un pintor quiere encontrar a dos

${ }^{11}$ La noción «no-ente» de Schelling es apropiada por Žižek para explicar el goce. Es una voluntad contractiva que apunta a lo interior frente a la voluntad expansiva de existencia, «siempre escapándose de la luz de la conciencia y por tanto, de pura razón, es precisamente lo carente de la regla» (CarrascoConde, 2003: 518).

12 «Courbet masterfully continued to dwell on the imprecise border that separates the sublime from the excremental: it becomes repulsive precisely on account of this excessive attraction» (Žižek, 2001a:37). 


\section{Yiyang Wu}

modelos de la alta sociedad para sus cuadros de lujo a fin de alcanzar la máxima autenticidad. Descubre que los modelos más adecuados son una pareja de mendigos, cuya imitación de los ricos es mucho más real. ${ }^{13}$

Otra película recomendada por el filósofo, The Thomas Crown Affair (1999), dirigida por John McTieman, narra la historia de un coleccionista millonario que encuentra la densidad de su vida robando cuadros como ladrón. El goce de él es «la aberración ontológica, el equilibrio perturbado que explica la transformación de nada en algo» (Žižek, 2011: 58). En La ventana indiscreta (1954) de Hitchcock, Jefferies halla su goce observando morbosamente los comportamientos de sus vecinos a través de la ventana. Se adueña de aquel mundo ficticio e imagina realidades que no existen, en contra de una vida tediosa representada por su novia perfecta, rigurosa y adinerada. El rechazo de Jefferies hacia ella y su obsesión voyerista reflejan las ganas de escaparse de lo simbólico. El encuentro mágico entre lo real, lo simbólico y lo imaginario sucede, cuando su novia es observada a través de la ventana, momento en que Jefferies se enamora inmediatamente de ella. En Orgullo y prejuicio de Jane Austen, Darcy y Elizabeth quieren mostrar al principio lo que quieren que muestren: un caballero orgulloso y una dama inteligente. Irónicamente cada uno recibe del otro su propio mensaje en forma invertida: para Darcy, Elizabeth se convierte en una mujer llena de pensamientos inútiles, y para esta, Darcy es un ser arrogante y despreciable. La chispa de amor sucede después de dejar de lado el prejuicio y enseñar al otro la parte más íntima y real de ellos.

La búsqueda de aquel punto ciego nos tienta y hace sufrir. Por eso, el goce no toma la forma de existencia sino insistencia: «lo que no existe, continúa insistiendo, tendiendo a la existencia» (Žižek, 2008a: 22). Žižek reinterpreta la frase polémica de «la mujer no existe» de Lacan. Para el sujeto femenino, hay que «no existir» como colectivo para escaparse de la subjetivación controlada por el discurso patriarcal, aferrándose al espacio innombrable, cuando el sistema intenta homogeneizar y unificar todas las disidencias. Afirma que el hombre "literalmente 'ex-siste': todo su ser se encuentra allí fuera, en la mujer. Esta, por su parte, no existe, insiste» (Žižek, 1994: 189). Frente al gran Otro que no deja de inventar nuevos discursos cautivadores, lo importante es la acción intermitente de búsqueda sin intención de llegar a la plenitud. En su análisis de un relato de Robert Sheckley, opina que el protagonista realiza su deseo «precisamente con esa traslación alucinada a un estado que le permitía posponer indefinidamente la satisfacción plena [...] un estado que reproducía la falta constitutiva del deseo» (Žižek, 2000: 24).

A veces dos goces contradictorios pueden atribuirse a la misma deficiencia estructural, dependiendo solamente de la ubicación de cada uno. El ejemplo que toma es Nadie nada nunca (1980) de Juan José Saer. Dos voces distintas se sobreponen para narrar el mismo suceso, técnica que constituye «la señalización de una mínima diferencia contra el fondo de la nada del contenido narrado» (Žižek, 2010:291). En The Parallax view, señala que Fitzgerald se empecina en corregir la estructura de Suave es la noche en la segunda edición aunque la versión corregida es peor que la original, porque se empeña en encontrar aquel punto crítico que le molesta: «like the two maps of

${ }^{13}$ El punctum es el objeto $a$ en la teoría fotográfica. Constituye un punto fotografiado casualmente que punza al sujeto en los momentos inesperados. Tantea y choca al espectador como a lgo que no se incluye en la intención original del fotógrafo, oponiéndose a la Studium (efecto a cordado entre el fotógra fo y el espectador) (Barthes, 1989). 
the same village in the example from Lévi-Strauss... The tickling object here is the absent Cause, the unfahomable $\mathrm{X}$ that undermines everynarrative solution» (Žižek, 2006: 19). ${ }^{14}$

Al encontrase con la cara espantosa de lo real, el goce se vuelve más horroroso que placentero. En el cuento «El inmortal» de Borges, lo real es el «horror sagrado» en la ciudad de los inmortales, erigida en el desierto secreto, que «contamina el pasado y el porvenin» (Borges, 2011: 34). La sociedad moderna intenta relegar este encuentro escandaloso con lo real. La esencia del famoso mandamiento bíblico «ama a tu prójimo como a ti mismo», reside en desplazar el encuentro con la cara espantosa del prójimo «insoportable, sofocante, cuya forma de gozar nos resulta demasiado molesta» (Žižek, 2011: 172). En la película Matrix, lo real es un desierto donde viven los excluidos por la sociedad, dispuestos a atacar al mundo simbólico lleno de simulacros y vigilancias omnipresentes. Žižek aprecia a los autores (Kafka, Marqués de Sade) y directores (Antonioni, Lynch) que gozan destapando las heridas traumáticas que quedan en la zona limbo. González Requena coincide con él, cuando analiza la película Blue Velvet de David Lynch: «si la conciencia es el órgano de la razón, de ello se reduce, entonces, una irracionalidad esencial del mundo» (González Requena, 2010: 13). Son creadores capaces de enfrentarse a los momentos oscuros y reales de la vida misma. Desafían también los códigos éticos establecidos, razón por la que el filósofo prefiere las películas que tratan el tema del amor imposible como El juego de lágrimas (un heterosexual y una travesti), o Strella (incesto). Es necesario pedir «una revolución sexual como realización definitiva de la revolución política» (Žižek, 2003a: 188).

En sus libros posteriores, el plus-de-goce difiere del goce como la única alternativa bajo los regímenes totalitarios. ${ }^{15}$ Es el cuestionamiento desesperado del sujeto cuando se ve atrapado en la fantasía capitalista que le desplaza perpetuamente de la realización del goce. Para Žižek, el sujeto Kafkiano está a la vez dentro y fuera de lo simbólico: la realización del goce depende de su admisión imposible al Otro, mientras que la determinación de encontrar el punto del goce lo distingue como un ser lúcido en el Sistema. En obras como El Castillo o El proceso, en vez de subordinarse pasivamente o salir del sistema, $\mathrm{K}$ insiste en entrar en él para descodificarlo. Consciente del fallo inevitable y el destino fatalista, disfruta de su pequeña lucha como plus-de-goce: «Si todo el mundo procura conocer la Ley — dice el hombre-. ¿Cómo es posible que durante tantos años sólo nadie más que yo te ha rogado que le dejes entrar? [...] (El guardián) le ruge al oído: Nadie más que tú tenías el derecho a entrar aquí, pues esta entrada estaba hecha sólo para ti» (Kafka, 1992: 320).

${ }^{14}$ En Antropología estructural, el antropólogo pide que los dos subgrupos dibujen el mapa de la tribu. Los conservadores pintan dos círculos concéntricos, mientras que los revolucionarios perciben su pueblo como un montón de casas separadas. Aquella diferencia se debe al intento común de los miembros de ignorar y tapar el trauma de la discrepancia social. Gozan de la visión de una tribu sin desencuentros, de «intema lizar un desequilibrio en las relaciones socia les que impedía que la comunidad se estabilizara como un todo armónico» (Žižek, 2006: 20).

${ }^{15}$ Señala la vinculación entre la noción plus-de-goce (plus-de-jouir) con el plusvalor marxista (Žižek, 2003a: 82). Ambas nociones se fijan en lo remanente y excesivo en el Sistema. Para Marx, el capitalismo se beneficia del plusvalor creado por los obreros. El sujeto se beneficia del «plus-de-goce» en el límite lógico-histórico del capita lismo: «el verdadero límite de la producción capita lista lo es el propio capital» (Žižek, 2003a: 82). El plusvalor es donde empieza a funcionar el capitalismo mientras que plusde-goce es elobjeto-causa que poneen funcionamiento la máquina deldeseobajo la sombra autoritaria. 


\section{Yiyang Wu}

Cabe mencionar también la aristocratización del goce y la disidencia antigua. El sistema capitalista sigue interiorizando y canonizando los elementos anteriormente subversivos. A lo largo de la historia literaria, las obras anteriormente escatológicas y eróticas, que funcionan como excepciones escandalosas contra la estética predominante de la época (Decameron, Ulises, Trópico de Cáncer), son estudiados luego por el círculo académico y dejan de ser un tabú público. En las letras hispánicas, los autores del «boom latinoamericano» pasan rápidamente de ser defensores de los desprestigiados a ser los padres de la literatura hispanoamericana. Algunos de ellos han renunciado a la posición radical de antaño. Para el propio filósofo, la única manera de no estar en aquel círculo vicioso es recelar siempre del propio deseo.

¡NO CEDER AL PROPIO DESEO!: HACIA LA PULSIÓN DE MUERTE Y EVOCAR LA FUERZA DE LO REAL

Freud relató una historia de su hija más pequeña: viendo que comer tarta puede complacer a sus padres, ella se entretiene haciéndolo, de tal modo que cada miembro de la familia quede contento en la historia. Para Žižek, es el tipo del goce falso porque «a través de la fantasía, la jouissance se domestica, se gentrifica» (Žižek, 2003a: 170). Como el sujeto lacaniano o la hija de Freud, siempre deseamos algo desde la otredad. La narrativa social es la versión multiplicada de la estructura familiar. Según la famosa fórmula «\$ $\diamond$ a» lacaniana, sabemos que el sujeto castrado desea el objeto a y el capitalismo contemporáneo lo manipula para incluirlo en la fantasía masiva: «organiza la escena en la que el goce del que estamos privados se concentra en el Otro que nos lo ha robado» (Žižek, 2011: 43). El sujeto no sabe identificar claramente su deseo y se ve obligado a hacer según el modo en que es interpelado. La fantasía capitalista, que «subyace en el texto ideológico público como su obsceno sostén no reconocido» (Žižek, 2011: 74), se encarga precisamente de prolongar aquel deseo inacabado contra la intrusión directa de lo real. Mediante la neutralización del saber, la manipulación ideológica del capitalismo contemporáneo se vuelve cada vez más sutil, totalitaria y autorreferencial: «hoy la forma ideológica predominante consiste en poner el acento en la lógica económica objetiva y despolitizada» (Žižek, 1998: 156).

Sin embargo, la visión nihilista que considera la subjetividad como consecuencia de la castración y el desconocimiento epistemológico, es refutada por los psicoanalíticos posteriores, porque causa «un derrumbe del deseo» (González Requena, 2012b: 134). Tanto Žižek como González Requena creen que la verdad es histórica, concreta y subjetiva (González Requena, 2012b: 132), y que la clave de desentrañar el mito ideológico es atravesar el deseo ambientado en la alteridad y «afrontar lo real de nuestro deseo» (Žižek, 2003c: 365). Cita la frase lacaniana «no ceder al propio deseo», para mostrar que la esencia en la lucha anticapitalista reside en la renuncia radical a todos los deseos gentrificados, asumiendo la forma de desear de manera «analítica». Hay que tener en cuenta la estructura interna del sistema que emite informaciones abstractas y objetivadas.

La forma de no manchar el deseo auténtico consiste en que «no toleres ningún sustituto de la Cosa; mantén la brecha del deseo abierta» (Žižek, 2016: 163), oponiéndose a todos los intentos de domesticación. Es necesario convertir nuestros goces en sustancias radicales e indomables y no dejarse seducir por las fantasías mansas con una «singularidad» dudable. Los insubordinados son los defensores de la excepción 
«aterradoramente despiadada, excluida del círculo de los sentimientos y consideraciones diarias, de las pasiones y temores» (Žižek, 2003b: 162). Al despertarse del letargo ideológico y romper con el encarcelamiento del orden simbólico, se da cuenta de la situación de orfandad y la pulsión de muerte. Según el filósofo, es «un automatismo de repetición ciego más allá de la búsqueda de placer, de la conformidad del hombre con su medio [...] esta dimensión de radical negatividad, no puede ser reducida a una expresión de las condiciones sociales enajenadas, sino que define la condition humaine en cuanto tal» (Žižek, 2003a: 27).

La pulsión de muerte no implica aquí la condición biológica, sino un ajuste de cuentas con nuestro pasado y la ruptura con la cadena de significantes que nos construyen anteriormente como sujeto socializado. Octavio Paz, inspirado en Más allá del principio de placer de Freud, habla de la obsesión de los mexicanos por la muerte como parte violenta e inherente de la mexicanidad: «nuestro culto a la muerte es culto a la vida, del mismo modo que el amor, que es hambre de vida, es anhelo de muerte» (Paz, 2007: 10). ${ }^{16}$ Aquella pulsión es el deseo del éxtasis y la esperanza de un desorden general en las fiestas desenfrenadas, que tiene una implicación más profunda que la muerte biológica. Para Žižek, el padre de Hamlet regresa como fantasma para interpelar a su hijo, porque todavía no ha muerto simbólicamente en la sociedad.

La obra Antígona de Sófocles funciona como ejemplo del movimiento político radical alentado por la pulsión de muerte. Polinices, el hermano de Antígona, traiciona al Estado y es desmembrado salvajemente por Creonte sin concederle un funeral digno. La prohibición del funeral de su hermano la atormenta en el exilio y le impulsa a tomar la decisión radical. Realiza las exequias de su hermano enfrentándose al poder del Estado y se suicida dignamente. Para el autor, la razón por la que Antígona se empecina en terminar el funeral de su hermano es la importancia de la muerte simbólica para la heroína. Canta en el rito funerario: «Si un esposo se muere, otro podría tener, y un hijo de otro hombre si hubiera perdido uno, pero cuando el padre y la madre están ocultos en el Hades no podría jamás nacer un hermano. Y así, según este principio, te he distinguido yo entre todos con mis honras» (Sófocles, 1981: 111). La singularidad de Polinices como un significante insustituible en el mundo simbólico hace que su hermana insista en un funeral oficial para él. La figura de Antígona no representa algo real, extrasimbólico, sino «el significante puro» y forma parte de la red simbólica. Se empeña en rebelarse contra el sistema, cuya pasión «encarna la pasión de muerte en estado puro» (Žižek, 2017: 15). A través del esfuerzo en fijar algo «expulsado» por la cadena de significantes, logra reestructurar el orden simbólico. Después de atravesar el fantasma ideológico, nos daremos cuenta de que «la formación de fantasía sólo enmascara, llena, un cierto lugar vacío en el Otro» (Žižek, 2010: 110). Dos mil años después, en la película El show de Truman, Truman queda en shock cuando descubre que su vida es un show en directo y decide valientemente salir de aquel mundo simbólico y terminar su rol cosificado.

Inevitablemente la pulsión de la muerte nos lleva a lo real, insondable como el agujero negro y lleno de pesadillas prenatales. Según González Requena: «si hubiera algún tipo de homogeneidad o de isomorfismo posible entre la conciencia y lo real que lo rodea, entonces la conciencia no se defendería de lo real, sino que se abriría a ello».

\footnotetext{
${ }^{16}$ Freud ha ana lizado la pulsión de muerte como la contraparte de la pulsión de vida, que guía al sujeto hacia el orden, la lógica y la regla. La pulsión de muerte se dirige hacia el interior como algo destructivo y a gresivo que conduce al sujeto a un estado primitivo, a nterior a la vida.
} 


\section{Yiyang Wu}

Afirma también el crítico español: «lo real es caos, mutación incesante y sin sentido, en la que todo se cambia constantemente y nada se repite más» (2010: 10 y 21). Súbitamente privado del apoyo de la estructura exterior, lo que descubre el sujeto es una realidad sin sentido común ni fundamento ontológico: «en cuanto se acerca demasiado a la verdad inconsciente, su yo se disuelve» (Žižek, 2000: 78).

Es más profundo que el sueño freudiano, que da cobijo a los sentimientos más recónditos del ser humano. En la serie de dibujos animados Tom and Jerry, el gato siempre persigue al ratón sin percibir el abismo adelante. Cuando la tierra desaparece bajo sus patas, al principio no cae, continúa corriendo. Cuando mira hacia abajo solo se asombra de ver que está flotando en el aire. El encuentro con lo real y el rechazo del nombre de padre son capaces de desgarrar cualquier ilusión, razón por la que el sujeto tiene que vivir de la fantasía fabricada por el mundo simbólico, con miedo a su propio resquebrajamiento. ${ }^{17}$ Como los pacientes que relatan el malestar ante el psicoanalista para reconstruir la personalidad, el sujeto necesita establecer de nuevo el lazo con el mundo después de la traumática muerte simbólica. A la izquierda le toca inventar el nuevo discurso, dice Paz: «en el mundo prenatal muerte y vida se confunden; en el nuestro, se oponen; en el más allá, vuelven a unirse, pero ya no en la ceguera animal [...] sino como inocencia reconquistada» (Paz, 2007: 69).

Cuando se publica El sublime objeto de la ideología en 1989, todavía no ha cesado el debate ideológico por la Guerra Fría y el triunfo de los movimientos independentistas del Tercer Mundo. Sin embargo, con el derrumbe del Muro de Berlín y el régimen soviético, parece que el capitalismo ha triunfado a escala global. Llegamos a una época del simulacro donde «se confunde inmediatez con transparencia, y transparencia con autenticidad»(Carrasco-Conde, 2003: 512), mientras que la sólida jerarquización social es protegida por los abstractos mecanismos discursivos. En vez de la lucha de clases, las cuestiones que protagonizan el panorama social son las que propone la teoría posmoderna (derecho LGBT, inmigración ilegal, ecología mundial).

Žižek advierte de que el problema de la distribución de recursos queda eclipsado bajo la apariencia homogénea y abstracta del capitalismo tardío. El capitalismo omnipresente incluso entra en el terreno de lo real y de lo inconsciente para dominar sobre nuestro deseo y miedo más profundo, de modo que la necesidad de la lucha anticapitalista sea cada vez más imperativa. Critica las corrientes filosóficas del Siglo XXI de desviar la necesidad de resolver el problema fundamental hacia las cuestiones parciales. Para él, las teorías feministas o ecologistas dejan de ser voces subversivas, porque se han convertido en consecuencias paralelas del capitalismo tolerante y solo abren el espacio para la autonomía correspondiente de aquellas luchas particulares, «lejos de imponer una violenta supresión de las diferencias» (Žižek, 2003b: 127). Analiza que el capitalismo aceptará la propuesta de los queers para apropiarse de su discurso y tapar el vacío estructural. ${ }^{18}$ Cita lo que propone Walter Benjamin en Tesis de

\footnotetext{
${ }^{17}$ Según Lacan, la psicosis se produce cuando «desde el campo del Otro, llega el llamado de un significante esencial que no puede ser a ceptado» (Lacan, 1984: 436).

${ }^{18}$ Aquellas luchas tienen el defecto de generalizarse sin tener en cuenta los casos concretos. En Iraq, the borrowed kettle, critica la apariencia neutral y profesional de los académicos norteamericanos, que opinan sobre la decisión política como un hecho factual: «The constitutive lie of the university discourse is that it disavows its performative dimension, presenting what effectively amounts to a political decision ba sed on power as a simple insight into the factual state of things» (Žižek, 2004: 139, la cursiva es mía). Muchos académicos radicales son conscientes del hecho de que la instrumentación directa de su demanda inundaría directamente en la pérdida de su privilegiada posición: «en este sentido, pueden
} 
filosofia de la historia: hay que hacer retornar y revitalizar el pasado como la evocación de lo reprimido, olvidado, y, sobre todo, real: «estamos todo el tiempo reescribiendo la historia, dando retroactivamente a los elementos su peso simbólico incluyéndolos en nuevos tejidos» (Žižek, 2003b: 88-89). No se trata de la simple repetición de los hechos, sino de una forma de estimular la fuerza desterritorializadora de lo real en la política actual, de fabricar «algo que anude el agujero de a castración, dado que los símboloscharlatanes- han fracasado allí» (González Requena, 2012a: 19).

En Bienvenidos al desierto de lo real, Žižek aborda la tremenda fuerza de lo real mediante un fragmento de Bertolt Brecht. Viendo desfilar los tanques soviéticos con ruidos ensordecedores en su camino hacia aplacar los disturbios obreros, se siente por primera vez impactado por las acciones del Partido Comunista. Lo que le cautiva no es el comunismo sino aquella violencia inmediata y que «la fuerza de la violencia como tal era vista y aceptada como una señal de autenticidad» (Žižek, 2008a: 11). Sabiendo que es imposible entrar plenamente en el mundo real, la estrategia que adopta el dramaturgo es mantener la distancia con ambos mundos e inyectar lo real, lo prohibido y lo enajenado en la realidad para lograr sorprender a los espectadores, llevándolos más allá de su sentido común. Para el dramaturgo, el distanciamiento teatral debe quitar a los espectadores la familiaridad que se vincula con algo predeterminado: «la representación distanciadora es aquella que permite reconocer el objeto, pero que lo muestra, al propio tiempo, como algo ajeno y distante» (Brecht, 1970: 42). Mediante la enajenación de la realidad fantasmagórica, se esfuerza por nombrar lo innombrable. Opina en La ópera de los dos centavos: "¿Qué es el asalto a un banco comparado con la fundación de un banco? ¿Qué es el asesinato comparado con el trabajo de oficina?» (Brecht, 1957: 51). La evocación de la fuerza destructiva de lo real causará cierta alteración en el presente estable, cimiento que sustenta la conciencia humana. Cuando se acercan al meollo traumático de lo real y se dan cuenta de lo ilusorio del mundo simbólico, existen sujetos que se colapsan. Lamenta Bruto en Julio César, en la noche previa a la conspiración (Shakespeare, 1921: 60):

¡Desde que Casio me excitó contra César no he podido dormir! ¡Entre la ejecución de un acto terrible y su primer impulso, todo el intervalo es como una visión o como un horrible sueño! ${ }_{\text {El }}$ espíritu y las potencias corporales celebran entonces consejo, y el estado del hombre, sedante a un pequeño reino, sufre entonces una verdadera insurrección!

Cuando se entera de que el parricidio le ha convertido en el traidor de la patria, Edipo se asombra e intenta suicidarse. En La ventana indiscreta, Jefferies obtiene placer imaginando mentalmente el homicidio del vecino que nunca ocurre de facto. Al final de la película, cuando aquel asesino soñado por él aparece en su habitación, lo que siente es puro horror y asombro. No podremos soportar el peso de la conciencia cuando nuestro deseo más obsceno aparezca en la realidad cotidiana. Por lo tanto, el filósofo cita una frase de Oscar Wilde: «iprotéjanos de los que queremos! [...] aceptar completamente la inconsistencia de nuestro deseo, aceptar completamente que es el propio deseo el que sabotea su propia liberación, es la amarga lección de Lacan» (Žižek, 2008b: 48). Tantear nuestro mundo más oscuro trae el derrumbe psicológico. En La

conservar hipócritamente su limpia conciencia moral mientras continúan disfrutando de su posición privilegia da »(Žižek, 2005: 64-65). 
casa negra de Patricia Highsmith, el desencantamiento del secreto colectivo conduce finalmente a la matanza grupal. ${ }^{19}$ Es imprescindible mantener la mínima sensación de realidad para no volverse esquizofrénico.

El término Aufheben (negación de la negación) en la dialéctica hegeliana se convierte así en la postura política que hay que adoptar: los conflictos y las negaciones que necesiten la actuación performativa del sujeto sirven para reconstruir nuestro marco conceptual en vez de arruinarlo completamente. La pulsión de morir «simbólicamente» es la postura neomarxista en el nuevo milenio, que aboga por la intrusión salvaje de las fuerzas inéditas y la transformación radical del sistema capitalista, mediante un acontecimiento que explique retroactivamente nuestro presente.

REINVENTAR LA IZQUIERDA: UNA INTERPRETACIÓN ŽIŽEKIANA DE LA NARRATIVA LATINOAMERICANA CONTEMPORÁNEA

Desde las primeras décadas del Siglo XX, la literatura hispanoamericana, sobre todo la poesía de vanguardia y postvanguardia, mantiene una relación intrínseca con el psicoanálisis freudiano, abordando lo inconsciente, oculto, onírico, extraño y desconocido. Abundan temas como el espejo, el sueño, el miedo, la introspección y la relación entre el yo y el otro. En el ámbito narrativo, los autores como Ernesto Sábato y Juan Carlos Onetti recurren a los imaginarios oscuros que reflejan la irracionalidad y la locura que existen como condición inherente al ser humano. Los títulos de los dos libros más famosos de ambos, El túnel del argentino y El pozo del uruguayo, encarnan la conciencia oscura y la condición solitaria del ser humano. Son novelas psicológicas impregnadas de matices existencialistas, poniendo énfasis en la condición individual en vez de la estructura social.

Publicada en 1940, La invención de Morel de Adolfo Bioy Casares se ha adelantado a su tiempo y a la teoría lacaniana. En la novela se vislumbran ya los tropos lacanianos y la imposibilidad del deseo mismo. Un prófugo venezolano exiliado en una isla perdida (lo real) se enamora de Faustine (lo imaginario), una mujer misteriosa que se desentiende de sus intentos por aproximarse a ella. El exiliado descubre luego que la mujer ideal no es más que una imagen cinematográfica proyectada por una máquina diseñada para perpetuar recuerdos (lo simbólico). Sin poder acercarse a la figura soñada, decide grabar su propia imagen antes de su muerte y mezclarla con la imagen de Faustine, invadiendo el terreno de lo simbólico. Al final de la novela se compara la inaccesible Faustine con la patria idealizada, opuesta a la realidad política lamentable del país: «que lleguemos a Venezuela; a otra Venezuela, porque para mí tú eres, Patria, los señores del gobiemo, las milicias con uniforme [...] sin embargo, te quiero, y desde mi disolución muchas veces te saludo» (Bioy Casares, 1992: 106). La relación sentimental entre el yo real y la amante simbólica se traduce en el compromiso del sujeto político hacia una Venezuela pendiente de mejorar. En obras como Zama de Antonio Di Benedetto, El solitario de amor de Cristina Peri Rossi, el encuentro con lo real sucede en el transcurso del exilio, cuando el sujeto pierde el lazo con la madre

${ }^{19}$ La casa negra en el cuento homónimo es elmito común entre los machos del pueblo y el lugar donde se practican las aventura s excitantes. Cuando un ingeniero ha revela do que la casa no es nada más que una choza miserable, se destruye el núcleo en que se proyecta la fanta sía colectiva y los hombres deciden matarlo. 
patria, viviendo una situación extraña y desencantada. En la novela autobiográfica En estado de memoria, Tununa Mercado relata que para «deslizarse de tema de arraigodesarraigo» (Mercado, 1990: 58), huye de las terapias en el exilio, alegando que los psicoanalistas quieren que se comporten como una enferma.

Con la caída de los ideales socialistas, la subida al poder de los gobiemos dictatoriales y la introducción de la teoría postfreudiana en el continente, durante los años 80 surgen la resignificación política del psicoanálisis y una posición más radical. En las obras de los escritores argentinos como Ricardo Piglia, Juan José Saer y Manuel Puig, la denuncia política siempre está acompañada de la reforma estilística y lingüística. En Respiración artificial, asistimos a una aglomeración de citas literarias, monólogos alucinados y hechos históricos que suceden diacrónicamente a lo largo de la historia universal. Todas aquellas digresiones e incoherencias literarias remiten al centro narrativo que es la violencia estatal argentina, hecho que no se narra explícitamente en la novela por la censura política. Logra «acolchonan» los hechos históricos para hacer alusión a la dictadura: «éramos antagónicos y estamos unidos. Yo, el escéptico, el hombre que vive fuera de la historia. Él, un hombre de principios, que solamente puede pensar desde la historia» (Piglia, 2013: 184). El ambiguo estilo lingüístico de la novela Glosa de Saer intenta mostrar la Nada a la que remiten los significantes: «Es, si se quiere, octubre, octubre o noviembre, del sesenta o del sesenta y uno, octubre tal vez, el catorce o el dieciséis [...] qué más da» (Saer, 2015: 11). Los fragmentos dispersos llenos de incertidumbre sirven como punto de partida de lo real para desafiar la hegemonía de la novela totalitaria y lineal, haciendo que el antiguo estilo narrativo se descomponga por dentro. No tiene un final concreto, sino que está postergándolo (o gozando) constantemente, con el fin de mostrar el centro vacío de la estructura novelística y la relación opaca entre palabras y cosas. ${ }^{20}$

La novela El beso de la mujer araña de Manuel Puig, que reivindica la coalición entre políticos de izquierda y homosexuales, procura legitimar la intrusión de lo prohibido y real en lo simbólico, a través de invertir los roles entre la nota al pie de página y el cuerpo del texto, entre el género folletinesco que representa el deseo desatado de la masa y la novela académica que pretende ser un discurso cerrado. La violencia de lo real literario consiste en la arbitrariedad de las notas adicionales, que funcionan como un sistema propio y no guardan relación ninguna con el contenido, hasta el punto de que ocupan más protagonismo que el propio texto. ${ }^{21}$

En las novelas de Diamela Eltit, Por la patria y El cuarto mundo, se recurre constantemente a la perspectiva salvaje y los balbuceos agresivos de los seres marginados que no están domesticados por el mundo falocéntrico y dictatorial. Sus obras posteriores (Jamás el fuego nunca) empiezan a reflexionar sobre una generación de izquierda fracasada que deja de comportarse como lo real subversivo y pasa a convertirse en un suplemento poco rebelde del capitalismo tolerante. Apuesta, en libros como Fuerzas Especiales y Sumar, por los grupos reales e insujetivables de la política

${ }^{20}$ La verdad en la narrativa de Saer se parece a la verdad žižekiana, que está en donde las pa labras no alcanzan: «Luego, según Botón, y, según Botón, según Washington; o bien: Todo esto, desde luego, según el Ma temático, más o menos [...]Pensándolo bien, nadie dice a lgo»(Saer, 2012: 95).

${ }^{21}$ En la nota pie de pá gina cita directamente a los psicoana listas ra dica les como Marcuse o J. C. Unwin, e introduce la evolución teórica de la sexualidad, desde los apologistas del carácter biológico de la sexualidad hasta los psicólogos que la estudian como un problema psicosocial. 


\section{Yiyang Wu}

actual, que son las prostitutas, mujeres indígenas y vendedoras ambulantes, sujetos que no pueden encontrar su representación en la cadena de significantes.

Las obras de los narradores que nacieron después de los 60 manifiestan una psicología anticapitalista más radical y muestran predilección por una lucha morbosa y gozosa contra el Sistema. En Sueños digitales del boliviano Edmundo Paz Soldán, Sebastián, experto en Photoshop, está encargado de retocar las fotos del presidente que puedan involucrarlo con el antiguo régimen dictatorial. Como forma de desobediencia, deja una indiscernible marca «S» en todas las fotos retocadas como su intrusión personal en el terreno del poder. Después de que el truco sea descubierto por el gobierno, sus huellas personales en el mundo son borradas sigilosamente: su correo es bloqueado, su tarjeta bancaria no funciona y alguien ha ocupado su puesto de trabajo... Al darse cuenta de su destino inexorable de «estar desaparecido» simbólicamente por el Otro, planifica una rebelión desesperada: decide suicidarse inmediatamente delante de la mirada pública, para no ser cancelado tan fácilmente de este mundo.

En Ciencias morales de Martín Kohan, María Teresa es la preceptora de un instituto y especialista en regular la conducta ética de los alumnos. Ella vive en una absoluta paranoia con respeto a los fumadores desobedientes que se reúnen en el baño masculino. Su goce se produce inesperadamente, cuando descubre que puede espiarlos mientras orinan, con la excusa de cumplir con su deber legítimo hasta el punto de que no se distingue entre un hábito oscuramente excitante y la aplicación excesivamente rigurosa de la regla. Como el cuadro de Courbet, lo anormal obsceno brota del cumplimiento excesivo de lo normal. En Wasabi del argentino Alan Pauls, la historia comienza con un pequeño quiste que crece en el cuerpo de un escritor acomodado que se encuentra en su crisis de la mediana edad. En la medida en que se encaja cada vez menos con la realidad simbólica, el pequeño malestar se engranda: su mujer lo ha abandonado por una nueva vida, su agente literario pierde la confianza en él, su ídolo literario lo ningunea en la feria y la crema homeopática que le recomienda su médico no sirve para nada. Encuentra un placer tóxico cuando entra en el reino prohibido: lame frecuentemente la crema recetada porque pica como wasabi (Pauls, 2005: 54). Este primer encuentro con lo real se encamina a un desenlace extraño: después de ser despojado de toda su pertenencia simbólica por unos ladrones callejeros, encuentra finalmente un espacio para su quiste y puede darle un sentido radical: lo utiliza para tener sexo con una prostituta callejera en la periferia de la ciudad. Para rebelarse, el sujeto rizomático tiene que apropiarse de los rincones aún no penetrados por el mundo de las palabras. En Las teorías salvajes de Pola Oloixarac, la invasión de lo real está en la determinación de romper con el contrato social de la belleza, ${ }^{22}$ en aceptar que el pacto con la animalidad es el cimiento que sustenta nuestra civilización, en el ataque a Google Map y la «Asociación de Orientación Lacaniana», en el ataque de los lumpemproletariados a las élites de izquierda «lacanomonacales» (Oloixarac, 2010: 154):

— ¿Sos político vos? ¿Eh, eh? —lo cacheteó, Collazo trató de esquivar sin suerte.

— ¡No, no! —yo no salía de mi obstinación. ¡No es un político! ¡Es sólo un intelectual de izquierda!

Cacha y Loki me miraron, lo miraron, y empezaron a pegarle más fuerte.

${ }^{22}$ En la novela una pareja rubia y solvente se empeña en tener sexo con dos nerds feos y muy estigmatizados por la estética social, por la simple voluntad de «querer hacerlo». 
La capacidad de cambiar el marco conceptual y la voluntad de «configurar lo real, simbólicamente, como un espacio humano que puede merecer la pena» (González Requena, 2012b: 134) han determinado la dimensión subversiva de un acontecimiento literario. Como menciona antes, el enfrentamiento directo con lo real trae peligros y angustias primitivas. En El pudor del pornográfico, una obra lacaniana según el mismo autor, la realidad en sí es obscena. Un escritor se dedica a responder minuciosa y dogmáticamente a las cartas pornográficas como modo de ganarse la vida. Está obsesionado por contemplar a la chica pudorosa que vive enfrente de su casa. Mantiene una relación platónica e imaginaria con ella para escaparse de la realidad obscena a que se ve obligado a enfrentarse. Cuando decide incursionar en el mundo de la vecina, sucede la mayor sorpresa: se da cuenta de que en aquella chica encarna su miedo más profundo porque es la persona más promiscua que ha conocido en su vida. Cabe preguntar, si es imprescindible o imprudente celebrar un acontecimiento que evoque toda la fuerza de lo real para cambiar la estructura social. Es el dilema que nos deja Ricardo Piglia cuando novela sobre el caso «Unabomben» y el manifiesto anticapitalista en El camino de Ida. ${ }^{23}$ Como Piglia, somos aquel sujeto inquietante que se encuentra siempre en el limbo de la acción política y la desilusión vital, vacilando en el intersticio de los dos mundos.

\section{CONCLUSIÓN}

Lo real, lo simbólico y lo imaginario son conceptos cruciales para entender la hipótesis lacaniana, resignificada luego por Žižek para aplicársela a los diversos ámbitos más allá del psicoanálisis como la literatura, el cine, la cultura popular y la política capitalista.

Para él, lo simbólico intersubjetivo se encarga de fabricar los deseos colectivos que orientan y naturalizan las acciones del sujeto alienado. Acomete contra la estructura social fantasmagórica, manipulada por el gran Otro que se sitúa en el centro de los significantes. Cuestiona las autoridades indiscutibles e indecibles en las obras literarias y cinematográficas. Incluso pone en entredicho la legitimidad del género literario y cinematográfico al explicar la lógica del acolchonamiento, mecanismo utilizado para tapar la ausencia estructural en la creación artística. La literatura clásica pierde el aura mística, mientras que las obras de la vanguardia/posvanguardia desempeñan la función de visibilizar la deficiencia fundamental del ser.

La existencia de objeto a representa el fracaso de la interpelación e indica una parte innombrable para el reino de las palabras. El goce se produce cuando el sujeto se escapa del dominio de lo simbólico con la ayuda de lo imaginario. La historia literaria y cinematográfica se caracteriza por el empeño constante de encontrar aquel punto de fuga donde pierde la validez el nombre del padre. Es un punto circunstancial difícil de precisar, cuyo encuentro con el sujeto trae experiencias gozosas que cobran forma de rebeliones performativas.

${ }^{23}$ El ca so Unabomber se refiere a la sesino serial Theodore Kaczynski, que tiene por objeto matar a varios científicos e intelectua les universitarios para propa gar su manifiesto anticapitalista en el que se analiza minuciosamente el problema del capitalismo actual y se propone un retomo definitivo a la sociedad preindustrial. 


\section{Yiyang Wu}

Para los escritores y directores en el capitalismo actual, resulta más que urgente atravesar la fantasía ideológica y política. Basado en la reinterpretación de Antígona de Sófocles, Žižek propone una revolución radical apelando a la pulsión simbólica de muerte. La transformación del establishment social necesita la configuración de lo real en el entramado simbólico, misión importante para la nueva generación de izquierda política y literaria. En las letras latinoamericanas, surge un grupo de autores de izquierda que deja de gozar escribiendo el trauma y va renovando su compromiso político. Los movimientos literarios del siglo XXI son temerosos, «a la vez activos y defensivos, del ser para explorar ese medio ambiente hostil que lo rodea» (González Requena, 2010: 11).

\section{OBRAS CITADAS}

Althusser, Louis (1988), Ideología y aparatos ideológicos del Estado, Buenos Aires, Nueva Visión.

Austen, Jane (2009), Orgullo y prejuicio, Barcelona, Alba.

Barthes, Roland (1989), La cámara lúcida, Barcelona, Paidós.

Beckett, Samuel (1995), Esperando a Godot, Barcelona, Tusquets.

Bioy Casares, Adolfo (1992), La invención de Morel, Buenos Aires, Ediciones Colihue.

Borges, Jorge Luis (2011), El Aleph, Barcelona, Penguim Random House.

Brecht, Bertolt (1957), La ópera de dos centavos, Buenos Aires, Ediciones Losange.

Brecht, Bertolt (1970), Escritos sobre Teatro (Tomo I), Buenos Aires, Nueva Visión.

Carrasco-Conde, Ana (2003), «Schelling, Žižek, Baudrillad: la lógica de fantasma», Anales del Seminario de Historia de la Filosofía, 30 (2), pp. 505-525.

Di Benedetto, Antonio (2002), Zama, Buenos Aires, Adriana Hidalgo.

Eagleton, Terry (1997), «iEnjoy!», London Review of Books, 19, pp. 7-9.

Eltit, Diamela (1986), Por la patria, Santiago, Ornitorrinco.

Eltit, Diamela (2011), El cuarto mundo, Santiago, Seix Barral.

Eltit, Diamela (2012), Jamás el fuego nunca, Cáceres, Periférica.

Eltit, Diamela (2015), Fuerzas especiales, Cáceres, Periférica.

Eltit, Diamela (2019), Sumar, Cáceres, Periférica.

Flaubert, Gustave (2014), Madame Bovary, Madrid, Siruela.

Freud, Sigmund (2007), La interpretación de los sueños, Madrid, Alianza.

Freud, Sigmund (2008), Más allá del principio del placer, Madrid, Alianza.

González Requena, Jesús (2010), «Lo real», Trama y fondo: revista de cultura, 29, pp. 8-28.

González Requena, Jesús (2012a), «El punto de quiebra del discurso lacaniano», Trama y Fondo: revista de cultura, 32, pp. 7-31.

González Requena, Jesús (2012b), «La verdad no es lo real, A propósito de la relación sexual que, se mire como se mire, existe», Trama y fondo: revista de cultura, 32, pp. 131-140.

González Requena, Jesús (2018), «La escena que aguarda», Trama y Fondo: revista de cultura, 44, pp. 31-79.

James, Henry (2011), The real thing, Londres, The Floating Press.

Kafka, Franz (1992), Obras escogidas, Santiago de Chile, Andrés Bello.

Klein, Melanie (1987), El psicoanálisis de niños, Barcelona, Paidós.

Kohan, Martín (2007), Ciencias morales, Barcelona, Anagrama.

Lacan, Jacques (1975), Las formaciones del inconsciente, Buenos Aires, Nueva visión.

Lacan, Jacques (1984), Las psicosis, Barcelona, Paidós.

Lacan, Jacques (1995), Aún, Buenos Aires, Paidós. 
Lacan, Jacques (2009), Escritos 2, México, Siglo XXI.

Lévi-Strauss, Claude (2000), Antropología estructural, Barcelona, Paidós.

Mercado, Tununa (1990), En estado de memoria, Montevideo, Ada Korn.

Oloixarac, Pola (2010), Las teorías salvajes. Barcelona, Alpha Decay.

Onetti, Juan Carlos (1969), El pozo, Montevideo, Arca.

Pauls, Alan (2005), Wasabi, Barcelona, Anagrama.

Pauls, Alan (2014), El pudor del pornográfico, Barcelona, Anagrama.

Paz, Octavio (2007), El laberinto de la soledad, Madrid, Fondo de Cultura Económica.

Paz Soldán, Edmundo (2001), Sueños digitales, Madrid, Alfaguara.

Peri Rossi, Cristina (1988), Solitario de amor, Barcelona, Grijalbo.

Piglia, Ricardo (2013), Respiración artificial, Madrid, Debolsillo.

Piglia, Ricardo (2017), El camino de Ida, Madrid, Debolsillo.

Puig, Manuel (2002), El beso de la mujer araña, Barcelona, Seix Barral.

Rendell, Ruth (1988), El árbol de manos, Madrid, Alfaguara.

Sábato, Ernesto (2018), El túnel, Barcelona, Seix Barral.

Saer, Juan José (2014), Nadie Nada Nunca, Barcelona, Rayo verde.

Saer, Juan José (2015), Glosa, Barcelona, Rayo verde.

Shakespeare, William (1921), Julio Cesar; Fausto, Madrid, Calpe.

Sófocles (1981), Tragedias, Madrid, Editorial Gredos.

Žižek, Slavoj (1994), ;Goza tu síntoma!: Jacques Lacan dentro y fuera de Hollywood, Buenos Aires, Nueva Visión.

Žižek, Slavoj y Fredric Jameson (1998), Estudios Culturales. Reflexiones sobre el multiculturalismo, Buenos Aires, Paidós.

Žižek, Slavoj (2000), Mirando al sesgo: una introducción a Jacques Lacan a través de la cultura popular, Buenos Aires, Paidós.

Žižek, Slavoj (2001a), The Fragile Absolute: Or, why is the Christian Legacy Worth Fighting For?, Londres, Verso.

Žižek, Slavoj (2001b), The fright of real tears: Krzystof Kieslowski between theory and posttheory, Londres, BFI Pub.

Žižek, Slavoj (2003a), La metástasis del goce: seis ensayos sobre la mujer y la causalidad, Buenos Aires, Paidós.

Žižek, Slavoj (2003b), El sublime objeto de la ideología, Buenos Aires, Siglo XXI.

Žižek, Slavoj (2003c), Ideología, un mapa de la cuestión, México, FCE.

Žižek, Slavoj (2004), Iraq: the borrowed kettle, Londres, Verso.

Žižek, Slavoj (2005), El títere y el enano: el núcleo perverso del cristianismo, Buenos Aires, Paidós.

Žižek, Slavoj (2006), The parallax view, Cambridge, MIT Press.

Žižek, Slavoj (2007), «Kant as a Theoretician of Vampirism», en Gilda Williams (ed.), The Gothic, Cambridge, MIT Press, pp.139-144.

Žižek, Slavoj (2008a), Bienvenidos al desierto de lo real, Madrid, Ediciones Akal.

Žižek, Slavoj (2008b), Cómo leer a Lacan, Buenos Aires, Paidós.

Žižek, Slavoj (2010), Lacan: los interlocutores mudos, Madrid, Ediciones Akal.

Žižek, Slavoj (2011), El acoso de las fantasías, Madrid, Ediciones Akal.

Žižek, Slavoj (2016), El resto indivisible, Buenos Aires, Ediciones Godot.

Žižek, Slavoj (2017), Antígona, Madrid, Ediciones Akal. 